\title{
Motile aeromonads from farmed and wild freshwater fish in northern Italy: an evaluation of antimicrobial activity and multidrug resistance during 2013 and 2016
}

Laura Borella ${ }^{1}$, Cristian Salogni ${ }^{1}$, Nicoletta Vitale ${ }^{1}$, Federico Scali ${ }^{1}$, Vittorio Maria Moretti ${ }^{2}$ (D), Paolo Pasquali ${ }^{3}$ and Giovanni Loris Alborali ${ }^{1}$

\begin{abstract}
Background: Antimicrobial resistant bacteria are emerging biological contaminants of the environment. In aquatic ecosystems, they originate mainly from hospitals, livestock manure and private households sewage water, which could contain antimicrobial agents and resistant microorganisms. Aeromonas spp. occur ubiquitously in aquatic environments and they cause disease in fish. Motile aeromonads are also associated with human gastrointestinal and wound infections and fish can act as a transmission route of antimicrobial resistance (AMR) aeromonads to humans. The environmental ubiquity, the natural susceptibility to antimicrobials and the zoonotic potential of Aeromonas spp. make them optimal candidates for studying the AMR in aquatic ecosystems.

Results: The AMR patterns of 95 motile aeromonads isolated from freshwater fish during 2013 and 2016 were analyzed. All samples from fish came from farms and natural water bodies located in northern Italy, which is an area characterized by high anthropic impact on the environment. The isolates were biochemically identified as Aeromonas hydrophila, Aeromonas sobria or Aeromonas caviae and AMR was determined by the standard disk diffusion method. All isolates were resistant to cloxacillin, spiramycin and tilmicosin. High AMR frequencies (> 95\%) were detected for tylosin, penicillin and sulfadiazine. AMR to danofloxacin, enrofloxacin, flumequine, ceftiofur, aminosidine, colistin, doxycycline, gentamicin, marbocyl and florfenicol was observed at low levels $(<10 \%)$. No AMR to cefquinome was found. Logistic regression showed several differences in antimicrobial activity between complexes. According to the source of aeromonads, only few differences in AMR between isolates from farmed and wild fish were observed.

Conclusions: Our data revealed an increasing trend of AMR to neomycin and apramycin among Aeromonas isolates during the study period, while resistance to erythromycin, tetracycline and thiamphenicol decreased. All isolates were multidrug resistance (MDR), but A. caviae showed the highest number of MDR per isolate. In most isolates, various degrees of MDR were detected to macrolides, quinolones, fluoroquinolones, polymyxins and cephalosporins (third and fourth generations), which are listed, by the World Health Organisation, to be among the highest priority and critically important antimicrobials in human medicine. Our findings underlined that freshwater fish can act as potential source of MDR motile aeromonads. Due to their zoonotic potential, this can pose serious threat to human health.
\end{abstract}

*Correspondence: vittorio.moretti@unimi.it

2 Department of Veterinary Medicine, University of Milan, Via dell'Università 6, 26900 Lodi, Italy

Full list of author information is available at the end of the article

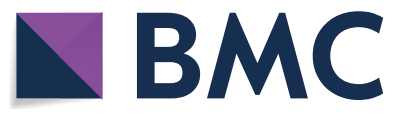

(c) The Author(s) 2020. This article is licensed under a Creative Commons Attribution 4.0 International License, which permits use, sharing, adaptation, distribution and reproduction in any medium or format, as long as you give appropriate credit to the original author(s) and the source, provide a link to the Creative Commons licence, and indicate if changes were made. The images or other third party material in this article are included in the article's Creative Commons licence, unless indicated otherwise in a credit line to the material. If material is not included in the article's Creative Commons licence and your intended use is not permitted by statutory regulation or exceeds the permitted use, you will need to obtain permission directly from the copyright holder. To view a copy of this licence, visit http://creativeco mmons.org/licenses/by/4.0/. The Creative Commons Public Domain Dedication waiver (http://creativecommons.org/publicdomain/ zero/1.0/) applies to the data made available in this article, unless otherwise stated in a credit line to the data. 
Keywords: Aquatic zoonosis, Critically important antimicrobials, Freshwater fish, Motile aeromonads, Multidrug resistance

\section{Background}

The environment is increasingly being recognized for the role it might play in the global spread of antimicrobial resistance (AMR). In particular, aquatic ecosystems may provide an ideal setting for the acquisition and spread of AMR because they are constantly exposed to anthropogenic changes such as sewage water from hospitals, private households and livestock manure. Among intensive type of livestock production, fish farms have a direct impact on the aquatic environment because antimicrobials in supplemented feed as therapeutic agents are added into the water. Drug residues typically remain in aquaculture environments and they may also be carried with effluents from production facilities into open waterways.

The genus Aeromonas comprises ubiquitous bacteria that occur normally in aquatic environments [1]. Therefore, they are constantly exposed to the action of micropollutants, such as residual antimicrobial compounds that may be present. Depending on their concentration, contaminating antimicrobials can exert a selective pressure and may thus favour the spread of AMR among aquatic bacterial populations [2].

Aeromonas spp. are best known as agents of fish diseases, but motile species are now emerging as important opportunistic human pathogens. They have been associated with several food-borne outbreaks and are progressively being isolated from patients with traveller's diarrhea [1]. The consumption of contaminated raw or cured fish and fish products is considered the main source of gastroenteritis. Most cases of the diseases that are reported are related to aquaculture products or cold-stored ready-to-eat food [3]. Moreover, motile Aeromonas spp. can cause skin and soft tissue infections as a result of injuries when handling fish or working in aquaculture and also when keeping fish as pets, for example as aquarium owners [4].

Given their zoonotic potential, the global rise in AMR of motile Aeromonas isolates from different sources may pose a serious threat to public health [59]. Despite the vast information on the AMR of motile aeromonads isolated from water, sediments and seafood $[5-7,10-12]$, few studies exist on the AMR patterns of isolates from fish, which are naturally exposed to these environmental microorganisms.

In order to fill this gap, the present work was designed to study the presence and the degree of AMR in motile aeromonads recovered from farmed and wild freshwater fish in northern Italy and to determine whether there are differences in AMR profiles between isolates from farmed and wild fish. The AMR of Aeromonas spp. over the 3-year period 2013-2016 was also evaluated. Finally, the presence of multidrug resistance (MDR), defined as the resistant to at least three classes of antimicrobials, was assessed.

\section{Methods}

\section{Collection of bacterial strains}

A total of 95 motile Aeromonas spp. isolates were included in this study. All isolates were recovered from internal tissues (liver, kidney, spleen, or brain) of 26 farmed fish and 69 wild fish of different freshwater species, submitted to the Laboratory of Diagnostic and Animal Health sector of the Istituto Zooprofilattico Sperimentale della Lombardia e dell'Emilia Romagna (IZSLER) in Brescia, Italy during the years 2013 and 2016. All fish samples came from farms and natural water bodies located in the Po River Valley (northern Italy), a geographical area characterized by high anthropic impact on the environment due to agricultural, livestock and industrial activities.

Bacterial strains were isolated on Tryptone Soya Agar (Oxoid, Italy) and Blood Agar (Oxoid, Italy) after $48 \mathrm{~h}$ of incubation at $22 \pm 2{ }^{\circ} \mathrm{C}$ in aerobic conditions.

\section{Phenotypic identification}

All Aeromonas isolates were identified at the genus level with a panel of tests according to Martin-Carnahan and Joseph [13]. Subsequently, Aeromonas isolates were biochemically typed at complex level by using previously published criteria [14]. According the Abbott scheme (Voges-Proskauer test, esculin hydrolysis, L-arabinose fermentation and gas production from glucose), each isolate was assigned to one of three traditionally recognized complex of motile Aeromonas spp.: Aeromonas hydrophila, Aeromonas sobria, and Aeromonas caviae.

The following reference strains were used in parallel with test isolates as positive/negative controls for the interpretation of doubtful biochemical reactions: Escherichia coli ATCC 25922, Pseudomonas aeruginosa ATCC 27853, Staphylococcus aureus ATCC 25923, Streptococcus agalactiae ATCC 27956, Klebsiella pneumonia ATCC 13883, Citrobacter freundii ATCC 43864, Salmonella enterica subsp. salamae (IZSLER 2009), Salmonella typhimurium ATCC 14028, Proteus mirabilis ATCC 29906, Listeria monocytogenes ATCC 13932. 
Stock cultures were maintained at $-20{ }^{\circ} \mathrm{C}$ in Trypticase Soy Broth medium (Oxoid, Italy) supplemented with glycerol at $20 \%(\mathrm{vol} / \mathrm{vol})$.

\section{Antimicrobial resistance}

Aeromonas isolates were tested for their susceptibility to a panel of 30 antimicrobials by the disk diffusion method on Mueller Hinton Agar (Oxoid, Italy) [15]. Antimicrobials frequently used in animal husbandry and human medicine were included in the study: aminosidine $(10 \mu \mathrm{g})$, amoxicillin $(25 \mu \mathrm{g})$, amoxicillin/clavulanic acid (AMC, $30 \mu \mathrm{g})$, ampicillin $(10 \mu \mathrm{g})$, apramycin $(15 \mu \mathrm{g})$, cephaloridine $(30 \mu \mathrm{g})$, cefquinome $(10 \mu \mathrm{g})$, ceftiofur $(30 \mu \mathrm{g})$, cloxacillin $(1 \mu \mathrm{g})$, colistin $(10 \mu \mathrm{g})$, danofloxacin $(5 \mu \mathrm{g})$, doxycycline $(30 \mu \mathrm{g})$, enrofloxacin $(5 \mu \mathrm{g})$, erythromycin $(15 \mu \mathrm{g})$, florfenicol $(30 \mu \mathrm{g})$, flumequine $(30 \mu \mathrm{g})$, gentamicin $(10 \mu \mathrm{g})$, kanamycin $(30 \mu \mathrm{g})$, marbofloxacin $(5 \mu \mathrm{g})$, nalidixic acid $(30 \mu \mathrm{g})$, neomycin $(30 \mu \mathrm{g})$, penicillin $(10 \mathrm{UI})$, spiramycin $(100 \mu \mathrm{g})$, sulfadiazine $(300 \mu \mathrm{g})$, tetracycline $(30 \mu \mathrm{g})$, thiamphenicol $(30 \mu \mathrm{g})$, tiamulin $(30 \mu \mathrm{g})$, tilmicosin $(15 \mu \mathrm{g})$, trimethoprim/sulfamethoxazole (SXT, $25 \mu \mathrm{g})$ and tylosin $(30 \mu \mathrm{g})$. All disks were supplied by Oxoid (Italy). Susceptibility tests were performed with the standard protocols (Clinical and Laboratory Standards Institute, CLSI) [16] using unmodified Mueller-Hinton media incubated at $22 \pm 2{ }^{\circ} \mathrm{C}$ for $24 \mathrm{~h}$, as suggested by Smith [17] for non-fastidious Gram-negative bacteria. The incubation conditions recommended in the standard methods for AMR testing of bacteria isolated from humans and farmed animals published by European Committee on Antimicrobial Susceptibility Testing (EUCAST) and CLSI were $35{ }^{\circ} \mathrm{C} \pm 2{ }^{\circ} \mathrm{C}$ for 16-20 h. However, many bacteria isolated from aquatic animals, and capable of causing infections in those animals, grow poorly or do not grow under these conditions. As a consequence, the standard methods for AMR testing of bacteria from aquatic sources recommend incubation at $28{ }^{\circ} \mathrm{C} \pm 2{ }^{\circ} \mathrm{C}$ for $24-28 \mathrm{~h}$ or $22 \pm 2{ }^{\circ} \mathrm{C}$ for $24-48 \mathrm{~h}$, depending on the species being examined [18]. An incubation temperature of $22^{\circ} \mathrm{C}$ was chosen because this temperature represents the standard isolation temperature of fish pathogens in our laboratory and was maintained in the AMR testing. It is worth to note that the disk diffusion method is not the recommended method in order to determine AMR to colistin. A joint EUCAST and CLSI subcommittee issued recommendations confirming that broth microdilution is so far the only valid method and that disk diffusion does not work because of the poor diffusion of the large colistin molecule [19]. On the basis of this strong limit, the results for colistin must be evaluated with caution and certainly the sensitivity to colistin need to be investigated with more suitable methods in the future. For those antimicrobials where interpretative criteria are not available for Aeromonas spp., Enterobacteriaceae susceptibility criteria were applied [20]. E. coli ATCC 35218 and E. coli ATCC 25922 were included as control strains. Isolates that were resistant to at least one agent in three or more antimicrobial classes were considered MDR [21].

\section{Statistical analysis}

The prevalence of AMR of motile Aeromonas strains was calculated and the binomial exact method was used to compute $95 \%$ confidence intervals $(95 \% \mathrm{CI})$. For each isolate the number of AMR was determined and used for further analysis. The association between AMR and Aeromonas complex (A. hydrophila, A. sobria, A. caviae), source of the isolates (farmed or wild fish), or sampling year $(2013,2016)$ was evaluated by a chi-square test $\left(x^{2}\right)$ or Fisher exact test when appropriate. Correlations between AMR profiles of Aeromonas spp. to tested antimicrobials were calculated by the Phi index. A logistic regression model was performed to calculate the probability for isolates to develop AMR due to the presence of each of the following variables: Aeromonas complex, strain source, year of sampling, and multidrug-resistant. For each test a $\mathrm{P}<0.05$ was considered statistically significant. All analyses were performed using $\mathrm{R}$ software ( $\mathrm{R}$ version 3.3.1, $\mathrm{R}$ Development Core Team [https:// www.R-project.org/]) [22].

\section{Results}

\section{Phenotypic identification and source of isolates}

All the isolates that were examined presented typical biochemical reactions and were allocated into one of three motile Aeromonas complexes. Of 95 Aeromonas isolates, $55.8 \%$ (53/95), 32.6\% (31/95) and 11.6\% (11/95) were identified as A. hydrophila, A. sobria, and A. caviae, respectively. A. hydrophila and $A$. sobria complexes were more prevalent within wild fish, with frequencies of $75.5 \%(40 / 53)$ and $80.6 \%(25 / 31)$, respectively, compared with $A$. caviae complex. Conversely, the latter was the most frequently isolated complex from farmed fish $(63.6 \%, 7 / 11)$. Those differences were significant $\left(\chi^{2}=8.47, P=0.0078\right)$. No differences were found between the prevalences of the three Aeromonas complexes in 2013 and $2016\left(\mathrm{x}^{2}=2.49, \mathrm{P}=0.2871\right)$.

\section{Antimicrobial resistance}

The AMR patterns of 95 Aeromonas isolates tested are shown in Table 1. All isolates were resistant to cloxacillin, spiramycin, and tilmicosin. High AMR frequencies $(>95 \%)$ were also observed for tylosin, penicillin and sulfadiazine. Conversely, resistances to danofloxacin, enrofloxacin, flumequine, ceftiofur, aminosidine, colistin, doxycycline, gentamicin, marbocyl, and florfenicol were 
Table 1 AMR profiles of Aeromonas isolates

\begin{tabular}{|c|c|c|c|c|c|}
\hline \multirow[t]{2}{*}{ Antimicrobials } & \multicolumn{4}{|c|}{ No. of resistant isolates (\%) } & \multirow{2}{*}{$\begin{array}{l}\text { Chi-square } \\
\text { index }\left(x^{2}\right)\end{array}$} \\
\hline & A. hydrophila & A. sobria & A. caviae & Total & \\
\hline Cloxacillin & $53(100)$ & $31(100)$ & $11(100)$ & $95(100)$ & / \\
\hline Spiramycin & $53(100)$ & $31(100)$ & $11(100)$ & $95(100)$ & / \\
\hline Tilmicosin & $53(100)$ & $31(100)$ & $11(100)$ & $95(100)$ & / \\
\hline Ampicillin* & $53(100)$ & $31(100)$ & $10(90.9)$ & $94(98.9)$ & 7.72 \\
\hline Tylosin & $53(100)$ & $30(96.8)$ & $11(100)$ & $94(98.9)$ & 2.09 \\
\hline Penicillin & $52(98.1)$ & $30(96.8)$ & $11(100)$ & $93(97.9)$ & 0.44 \\
\hline Sulfadiazine* & $53(100)$ & $28(90.3)$ & $11(100)$ & $92(96.8)$ & 6.40 \\
\hline Amoxicillin & $52(98.1)$ & $30(96.8)$ & $10(90.9)$ & $92(96.8)$ & 1.55 \\
\hline Tiamulin** & $48(90.6)$ & $22(71.0)$ & $11(100)$ & $81(85.3)$ & 8.13 \\
\hline Neomycin** & $27(50.9)$ & $26(83.9)$ & $4(36.4)$ & $57(60.0)$ & 11.73 \\
\hline Erythromycin ${ }^{* * *}$ & $35(66.0)$ & $9(29.0)$ & $11(100)$ & $55(57.9)$ & 20.04 \\
\hline Cephaloridine ${ }^{* * *}$ & $38(71.7)$ & $3(9.7)$ & $10(90.9)$ & $51(53.7)$ & 37.19 \\
\hline $\mathrm{AMC}$ & $27(50.9)$ & $11(35.5)$ & $5(45.5)$ & $43(45.3)$ & 1.89 \\
\hline Apramycin ${ }^{* * *}$ & $16(30.2)$ & $23(74.2)$ & 0 & $39(41.1)$ & 24.32 \\
\hline Tetracycline $e^{* *}$ & $12(22.6)$ & $1(3.2)$ & $5(45.5)$ & $18(8.9)$ & 10.49 \\
\hline SXT** & $14(26.4)$ & 0 & $2(18.2)$ & $16(16.8)$ & 9.76 \\
\hline Nalidixic acid* & $12(22.6)$ & 0 & $3(27.3)$ & $15(15.8)$ & 8.77 \\
\hline Thiamphenicol* & $11(20.8)$ & 0 & $2(18.2)$ & $13(13.7)$ & 7.35 \\
\hline Kanamycin & $5(9.4)$ & $6(19.4)$ & 0 & $11(11.6)$ & 3.51 \\
\hline Danofloxacin & $7(13.2)$ & 0 & $2(18.2)$ & $9(9.5)$ & 5.08 \\
\hline Enrofloxacin*** & $4(7.5)$ & 0 & $4(36.4)$ & $8(8.4)$ & 14.04 \\
\hline Flumequine & $5(9.4)$ & 0 & $2(18.2)$ & $7(7.4)$ & 4.68 \\
\hline Ceftiofur*** & $1(1.9)$ & $1(3.2)$ & $4(36.4)$ & $6(6.3)$ & 19.04 \\
\hline Aminosidine ${ }^{*}$ & $1(1.9)$ & $5(16.1)$ & 0 & $6(6.3)$ & 7.54 \\
\hline Colistin & $4(7.5)$ & $2(6.5)$ & 0 & $6(6.3)$ & 0.88 \\
\hline Doxycycline $e^{* *}$ & $2(3.8)$ & 0 & $3(27.3)$ & $5(5.3)$ & 12.64 \\
\hline Gentamicin & $3(5.7)$ & 0 & 0 & $3(3.2)$ & 2.45 \\
\hline Marbocyl & $3(5.7)$ & 0 & 0 & $3(3.2)$ & 2.45 \\
\hline Florfenicol & $2(3.8)$ & 0 & $1(9.1)$ & $3(3.2)$ & 2.34 \\
\hline Cefquinome & 0 & 0 & 0 & 0 & / \\
\hline
\end{tabular}

Significant differences between Aeromonas complexes were indicated by: ${ }^{*} \mathrm{P}<0.05$, ${ }^{*} \mathrm{P}<0.01$, ${ }^{* * *} \mathrm{P}<0.001$

observed at low levels $(<10 \%)$. None of the isolates were found to be resistant to cefquinome.

Considering the antimicrobial classes, Aeromonas isolates showed the highest levels of AMR to macrolides (100\%), penicillins (100\%), sulfonamides (96.8\%), and pleuromutilins (83.5\%). Aminoglycoside resistance was also frequently detected (62.1\%), while resistance to polymyxins and cephalosporins (third and fourth generations) was observed rarely (6.3\%).

With regard to different Aeromonas complexes, variable profiles of AMR existed. Significant differences in AMR patterns were observed for 15 antimicrobials: aminosidine, ampicillin, apramycin, ceftiofur, cephaloridine, doxycycline, enrofloxacin, erythromycin, nalidixic acid, neomycin, sulfadiazine, SXT, tetracycline, thiamphenicol and tiamulin. In particular, strong associations were found between the complex $A$. caviae and resistance to apramycin $(\mathrm{Phi}=0.51)$. In a multivariate analysis of data, complex-related variability resulted in statistical significance only for four agents: aminosidine, cephaloridine, ceftiofur, and neomycin. For the others, the effect of strain source or sampling year on AMR was stronger than that of belonging to a specific complex. The probability of observing AMR to aminosidine (OR 188.6, 95\% CI 2.8-inf) and neomycin (OR 1.6, 95\% CI 1.1-2.2) was higher in A. sobria than in the other two complexes. The probability of detecting resistance to cephaloridine was higher in A. caviae and A. hydrophyla than in an $A$. sobria complex (OR 30.2, 95\% CI 7.5-121.9). Finally, the probability of finding AMR to ceftiofur was higher in $A$. caviae than the other two complexes (OR 17.1, 95\% CI 1.7-178.1).

AMR patterns of Aeromonas spp. recovered from farmed and wild freshwater fish are displayed in Table 2. According to the source of isolates, significant differences in AMR frequencies were found for five agents: apramycin, doxycycline, nalidixic acid, sulfadiazine and tetracycline.

Nevertheless, according to multivariate analysis, the effects on the source of isolates in the AMR results were statistically significant only for three antimicrobials: nalidixic acid, apramycin, and tetracycline. Aeromonas spp. recovered from farmed fish showed a probability to be resistant to nalidixic acid that was about four times higher when compared to wild isolates (OR 3.9, 95\% CI 1.3-12.3). Likewise, isolates of farmed origin were twice as likely to be resistant to tetracycline when compared to wild isolates (OR 2.1, 95\% CI 1.4-3.2). Finally, isolates of wild origin exhibited a four times higher probability to be resistant to apramycin than farmed isolates (OR 4.2, 95\% CI 1.4-12.6).

Statistical differences in AMR between Aeromonas spp. isolated in 2013 and 2016 were detected (Table 3). Overall, the isolates showed a significant increase in resistance to neomycin, AMC and apramycin while resistance to erythromycin, tetracycline, and thiamphenicol significantly decreased during the study period.

No significant changes in AMR among farmed isolates were observed over the study period, with the exception of resistance to amoxicillin, which increased from $66.7 \%$ in 2013 to $100 \%$ in 2016 ( $\mathrm{Phi}=0.53$ ) (data not shown). In contrast, a significant increase in resistance to neomycin, AMC, and apramycin among Aeromonas spp. from wild fish was observed during the study period while resistance to erythromycin, tetracycline and thiamphenicol significantly decreased (data not shown). 
Table 2 AMR profiles of Aeromonas isolates recovered from farmed and wild freshwater fish

\begin{tabular}{llll}
\hline Antimicrobials & \multicolumn{2}{l}{ No. of resistant isolates (\%) } & $\begin{array}{l}\text { Chi- } \\
\text { square } \\
\text { index ( } \mathbf{X}^{2} \text { ) }\end{array}$ \\
\cline { 2 - 3 } & Farmed fish & Wild fish & \\
\hline Cloxacillin & $26(100)$ & $69(100)$ & $/$ \\
Spiramycin & $26(100)$ & $69(100)$ & $/$ \\
Tilmicosin & $26(100)$ & $69(100)$ & $/$ \\
Ampicillin & $25(96.2)$ & $69(100)$ & 0.26 \\
Tylosin & $25(96.2)$ & $69(100)$ & 0.26 \\
Penicillin & $24(92.3)$ & $69(100)$ & 2.33 \\
Sulfadiazine* & $23(88.5)$ & $69(100)$ & 4.88 \\
Amoxicillin & $24(92.3)$ & $68(98.6)$ & 0.79 \\
Tiamulin & $19(73.1)$ & $62(89.9)$ & 3.00 \\
Neomycin & $15(57.7)$ & $42(60.9)$ & 0 \\
Erythromycin & $14(53.8)$ & $41(59.4)$ & 0.07 \\
Cephaloridine & $13(50.0)$ & $38(55.1)$ & 0.05 \\
AMC & $10(38.5)$ & $33(47.8)$ & 0.34 \\
Apramycin* & $6(23.1)$ & $33(47.8)$ & 3.81 \\
Tetracycline** & $10(38.5)$ & $8(11.6)$ & 7.21 \\
SXT & $3(11.5)$ & $13(18.8)$ & 0.29 \\
Nalidixic acid* & $8(30.8)$ & $7(10.1)$ & 4.59 \\
Thiamphenicol & $2(7.7)$ & $11(15.9)$ & 0.50 \\
Kanamycin & $1(3.8)$ & $10(14.5)$ & 1.18 \\
Danofloxacin & $5(19.2)$ & $4(5.8)$ & 2.56 \\
Enrofloxacin & $4(15.4)$ & $4(5.8)$ & 1.18 \\
Flumequine & $4(15.4)$ & $3(4.3)$ & 1.95 \\
Ceftiofur & $2(7.7)$ & $4(5.8)$ & 0 \\
Aminosidine & 0 & $6(8.7)$ & 1.17 \\
Colistin & 0 & $6(8.7)$ & 1.17 \\
Doxycycline*** & $5(19.2)$ & 0 & 10.42 \\
Gentamicin & $2(7.7)$ & $1(1.4)$ & 0.79 \\
Marbocyl & $2(7.7)$ & $1(1.4)$ & 0.79 \\
Florfenicol & $2(7.7)$ & $1(1.4)$ & 0.79 \\
Cefquinome & 0 & 0 & $/$ \\
\hline Significant & & & \\
\hline
\end{tabular}

Significant differences between Aeromonas isolates of farmed and wild origin were indicated by: ${ }^{*} \mathrm{P}<0.05$, ${ }^{* *} \mathrm{P}<0.01$, ${ }^{* * *} \mathrm{P}<0.001$

\section{Multidrug resistance}

Regardless of Aeromonas complex and the source of Aeromonas spp., all isolates were MDR. Moreover, each isolate showed a pattern of resistance to at least seven antimicrobials. The mean resistance value to tested antimicrobials was 12.7 ( $\pm 2.7 \mathrm{ds}$; range $7-2$; median 13 ). The minimum number of resistances (seven antimicrobials) was observed in two isolates, both belonging to the $A$. sobria complex. The maximum number of resistances $(22$ antimicrobials) was found in one isolate, belonging to the A. hydrophila complex. Figure 1 shows the distribution of AMR per each Aeromonas isolate by sampling year, complex and source. Our results indicated that there was a
Table 3 AMR profiles of Aeromonas spp. isolated in 2013 and 2016

\begin{tabular}{|c|c|c|c|}
\hline \multirow[t]{2}{*}{ Antimicrobials } & \multicolumn{2}{|c|}{ No. of resistant isolates (\%) } & \multirow{2}{*}{$\begin{array}{l}\text { Chi- } \\
\text { square } \\
\text { index }\left(x^{2}\right)\end{array}$} \\
\hline & 2013 & 2016 & \\
\hline Cloxacillin & $31(100)$ & $64(100)$ & / \\
\hline Spiramycin & $31(100)$ & $64(100)$ & / \\
\hline Tilmicosin & $31(100)$ & $64(100)$ & / \\
\hline Ampicillin & $30(96.8)$ & $64(100)$ & 0.14 \\
\hline Tylosin & $31(100)$ & $63(98.4)$ & 0 \\
\hline Penicillin & $31(100)$ & $62(96.9)$ & 0.05 \\
\hline Amoxicillin & $29(93.5)$ & $63(98.4)$ & 0.43 \\
\hline Sulfadiazine & $31(100)$ & $61(95.3)$ & 0.36 \\
\hline Tiamulin & $27(87.1)$ & $54(84.4)$ & 0 \\
\hline Neomycin** & $12(38.7)$ & $45(70.3)$ & 7.42 \\
\hline Erythromycin** & $25(80.6)$ & $30(46.9)$ & 8.43 \\
\hline Cephaloridine* & $23(74.2)$ & $28(43.8)$ & 6.61 \\
\hline $\mathrm{AMC}^{*}$ & $8(25.8)$ & $35(54.7)$ & 5.91 \\
\hline Apramycin** & $6(19.4)$ & $33(51.6)$ & 7.67 \\
\hline Tetracycline* & $10(32.3)$ & $8(12.5)$ & 4.1 \\
\hline SXT & $8(25.8)$ & $8(12.5)$ & 1.78 \\
\hline Nalidixic acid & $5(16.1)$ & $10(15.6)$ & 0 \\
\hline Thiamphenicol** & $9(29.0)$ & $4(6.3)$ & 7.35 \\
\hline Kanamycin & $2(6.5)$ & $9(14.1)$ & 0.56 \\
\hline Danofloxacin & $1(3.2)$ & $8(12.5)$ & 1.15 \\
\hline Enrofloxacin & $4(12.9)$ & $4(6.3)$ & 0.49 \\
\hline Flumequine & $1(3.2)$ & $6(9.4)$ & 0.43 \\
\hline Aminosidine & $1(3.2)$ & $5(7.8)$ & 0.17 \\
\hline Colistin & $1(3.2)$ & $5(7.8)$ & 0.17 \\
\hline Ceftiofur & $2(6.5)$ & $4(6.3)$ & 0 \\
\hline Doxycycline & $2(6.5)$ & $3(4.7)$ & 0 \\
\hline Florfenicol & 0 & $3(4.7)$ & 0.36 \\
\hline Gentamicin & $1(3.2)$ & $2(3.1)$ & 0 \\
\hline Marbocyl & $1(3.2)$ & $2(3.1)$ & 0 \\
\hline Cefquinome & 0 & 0 & / \\
\hline
\end{tabular}

Significant differences between Aeromonas spp. isolated in 2013 and 2016 were indicated by: ${ }^{*} \mathrm{P}<0.05 ;{ }^{* *} \mathrm{P}<0.01 ;{ }^{* * *} \mathrm{P}<0.001$

tendency towards a higher number of resistances among A. caviae isolates compared to other two complexes, both in 2013 and 2016. Considering the source of Aeromonas spp., an increase in resistance rates among isolates from farmed fish was observed during the study period, while isolates of wild origin tended to exhibit the same pattern over the time.

\section{Discussion}

In this study, fish isolates of motile Aeromonas spp. from northern Italy displayed high levels of resistance to various antimicrobials agents. Regardless of Aeromonas complex, resistance to penicillins, macrolides, pleuromutilins 


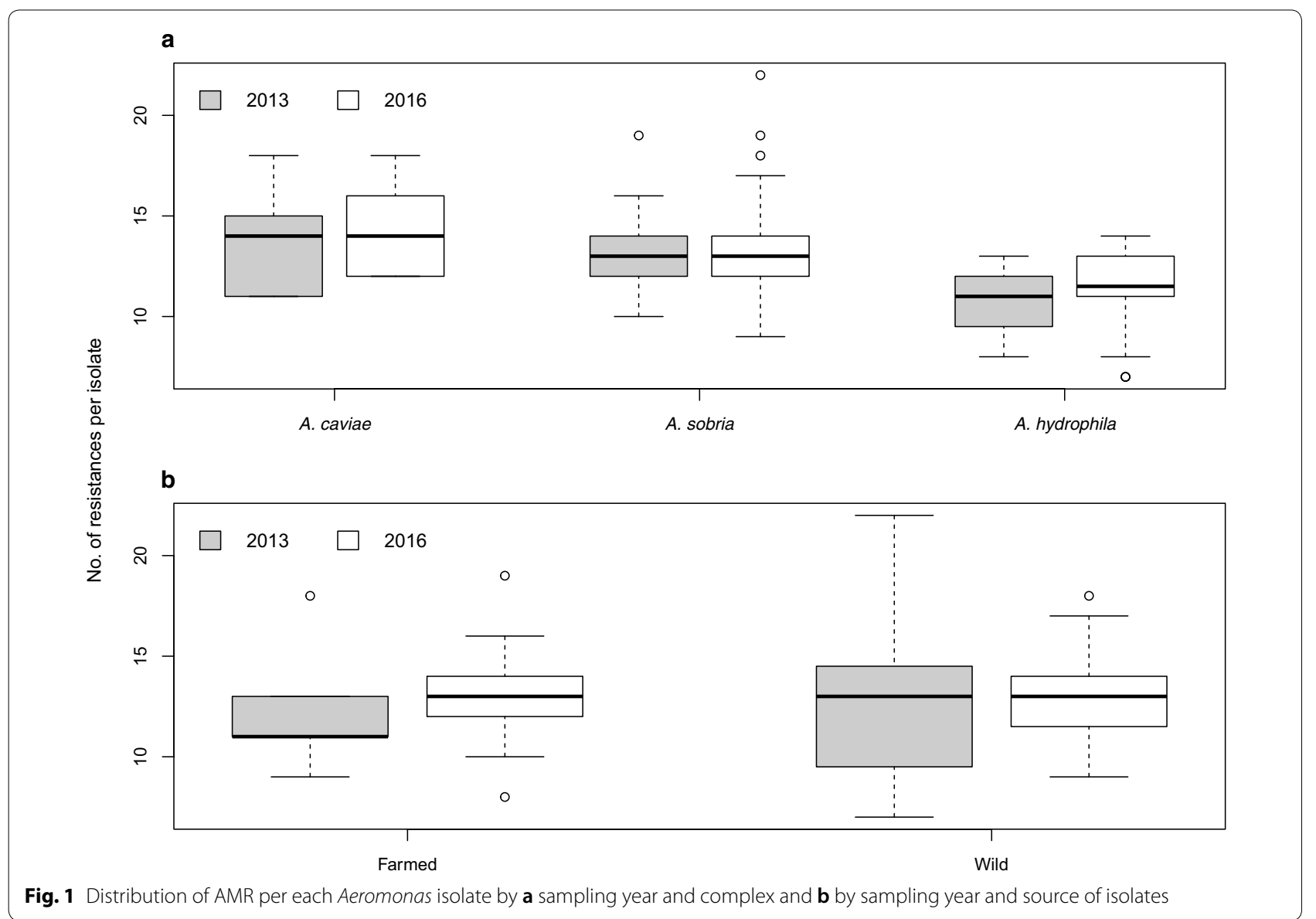

and sulfonamides was particularly widespread and it was detected in all or almost all the isolates. The high resistance to penicillins observed here is in agreement with the intrinsic resistance of Aeromonas species to beta-lactams widely reported in the literature; in fact, Aeromonas bacteria are known to be intrinsically resistant to aminopenicillins and first generation cephalosporins.

This is due to the production of multiple, inducible, chromosomally encoded beta-lactamases [23, 24]. According to the source of isolates, very few differences in AMR rates were observed between aeromonads recovered from farmed and wild fish. Among antimicrobials registered for use in Italian aquaculture and tested here (i.e., amoxicillin, flumequine, SXT, tetracycline), only tetracycline showed higher AMR in isolates from farmed fish than those from wild ones. Moreover, except for amoxicillin, no significant trend of increased resistance among isolates of farmed origin was observed during the study period. These results suggest that the antimicrobial use in aquaculture should not be the only contributing factor considered when evaluating the AMR of Aeromonas species from fish.
Excluding the intrinsic AMR to beta-lactams, the high AMR frequencies observed here could be explained by acquired mechanisms involving the transfer of antibiotic resistance genes (ARGs) from other aquatic bacteria [25]. In this research, all sampling sites (fish farms and natural water bodies) are located near urban centres and livestock-producing areas. Thus, it is possible that some of the AMR resulted from the release of AMR bacteria and drugs residues from urban and animal wastewater being discharged into the aquatic ecosystems and their variations could reflect local antimicrobial usage. Once these bacteria are in the water environment, the exchange of ARGs among aquatic microorganisms through mobile genetic elements (MGEs), such as plasmids, is readily facilitated [26]. This outcome can result in a higher frequency of MDR isolates. There is concern that ARGs are widespread not only among clinical pathogens but also in environmental bacteria, as a consequence of the wide usage of antimicrobials in clinical practice, animal husbandry and agriculture [26-28].

With regard to Aeromonas complexes, our data revealed the presence of significant differences in the AMR, suggesting that phenotypic identification of motile 
aeromonads at complex level may be useful in clinical practice for the selection of the first line of antimicrobial to be administered in infections caused by these bacteria. Moreover, phenotypic methods have the advantage of being particularly suitable for use in diagnostic routine activity because it uses standard biochemical tests [14].

However, it is worth noting that AMR profiles of isolates tested showed a considerable high variability, which is likely due to the relatively small number of isolates included in the research. This can potentially affect the reliability of the results, which may not reflect the real resistance patterns of Aeromonas populations in freshwater habitats. Thus, data on AMR of these microorganisms should be further investigated through epidemiological studies based on a larger sample size.

The frequent occurrence of MDR aeromonads observed in this study is of concern considering the ubiquitous nature and the potential role as reservoir of ARGs of Aeromonas spp. [27, 29]. Motile species also have a zoonotic potential, causing gastroenteritis, skin and soft tissue infection, and bacteraemia in immunocompromised patients [1]. In this regard, the detection of various degrees of resistance even to drugs listed in the highest priority, critically important antimicrobial classes in human medicine (macrolides, quinolones, fluoroquinolones, polymyxins, third and fourth generations of cephalosporins) [30] is of particular concern. Among these classes, quinolones are even considered the antimicrobials of choice to treat human Aeromonas infections [31].

\section{Conclusions}

Our findings contribute to highlight the role of freshwater fish as reservoir of MDR motile Aeromonas spp., which can represent a potential hazard to consumers via food-borne infections and a risk factor for wound infections after handling contaminated fish (e. g. in the case of aquaculture workers, fish handlers, or aquarium owners).

The broad distribution of these bacteria in different habitats remains a relevant public health issue. Therefore, there should be a continuous and regular effort to monitor the dissemination of resistant aeromonads in aquatic ecosystems on a global scale, evaluating different environmental sources.

\section{Prior publication}

Data have not been published previously.

\section{Authors' contributions}

LB participated in the design of the study, acquisition of data, performed the analyses and drafted the manuscript. CS participated to the design of the study, arranged for access to the database samples, and helped with writing the manuscript and interpreting the results. NV, FS assisted with the statistical analysis and interpretation of the results. PP participated in the design of the study, performed the analyses and drafted the manuscript. VMM contributed to the preparation of the manuscript. GLA supervised the project and helped in discussing results and manuscript preparation. All authors read and approved the final manuscript.

\section{Funding}

This research received no specific grant from any funding agencies in the public, commercial, or not-for-profit sectors.

\section{Availability of data and materials}

The datasets used and/or analysed during the current study are available from the senior (last) author on reasonable request.

\section{Ethics approval and consent to participate}

This study did not require official or institutional ethical approval.

Consent for publication

Not applicable.

\section{Competing interests}

The authors declare that they have no competing interests.

\section{Author details}

${ }^{1}$ Istituto Zooprofilattico Sperimentale della Lombardia e dell'Emilia Romagna "Bruno Ubertini", Via Bianchi 9, 25124 Brescia, Italy. ${ }^{2}$ Department of Veterinary Medicine, University of Milan, Via dell'Università 6, 26900 Lodi, Italy. ${ }^{3}$ Department of Veterinary Public Health and Food Safety, Istituto Superiore di Sanità, Viale Regina Elena 299, 00161 Rome, Italy.

Received: 17 July 2019 Accepted: 14 January 2020

Published online: 23 January 2020

\section{References}

1. Janda JM, Abbott SL. The genus Aeromonas: taxonomy, pathogenicity, and infection. Clin Microbiol Rev. 2010;23:35-733.

2. Stratev D, Daskalov H, Vashin I. Characterisation and determination of antimicrobial resistance of $\beta$-haemolytic Aeromonas spp. isolated from common carp (Cyprinus carpio L.). Rev Méd Vét. 2015;2015(166):54-61.

3. Daskalov H. The importance of Aeromonas hydrophila in food safety. Food Control. 2006;17:474-83.

4. Lehane L, Rawlin GT. Topically acquired bacterial zoonoses from fish: a review. Med J Aust. 2000;173:256-9.

5. Patil HJ, Benet-Perelberg A, Naor A, Smirnov M, Ofek T, Nasser A, et al. Evidence of increased antibiotic resistance in phylogenetically-diverse Aeromonas isolates from semi-intensive fish ponds treated with antibiotics. Front Microbiol. 2016;7:1-12.

6. Lijon MB, Khatun MM, Islam A, Khatun MM, Islam MA. Detection of multidrug resistance Aeromonas hydrophila in farm raised fresh water prawns. J Adv Vet Anim Res. 2015;2:469-74.

7. Gordon L, Giraud E, Ganière JP, Armand F, Bouju-Albert A, De La Cotte N, et al. Antimicrobial resistance survey in a river receiving effluents from freshwater fish farms. J Appl Microbiol. 2007;102:1 167-76.

8. Palù Peres A, Martins Gomes L, Lemos Miguel MA, Teruzkin Balassiano I, Penna Queiroz ML, Correâ Freitas-Almeida A, et al. Antimicrobial resistance in food and clinical Aeromonas isolates. Food Microbiol. 2006;23:504-9.

9. Hatha M, Vivekanandhan AA, Joice GJ. Antibiotic resistance pattern of motile aeromonads from farm raised fresh water fish. Int J Food Microbiol. 2005;98:131-4.

10. Ottaviani D, Santarelli S, Bacchiocchi S, Masini L, Ghittino C, Bacchiocchi I. Occurrence and characterization of Aeromonas spp. in mussels from the Adriatic Sea. Food Microbiol. 2006;23:418-22.

11. Huddleston JR, Zak JC, Jeter RM. Antimicrobial susceptibilities of Aeromonas spp. isolated from environmental sources. Appl Environ Microbiol. 2006; $72: 7036-42$.

12. Goni-Urriza M, Capdepuy M, Arpin C, Raymond N, Caumette P, Quentin C. Impact of an urban effluent on antibiotic resistance of riverine Enterobacteriaceae and Aeromonas spp. Appl. Environ Microbiol. 2000;66:125-32.

13. Martin-Carnahan A, Joseph SW. Family I Aeromonadaceae. In: Garrity G, Bell J, Lilburn T, editors. Bergey's manual of systematic bacteriology. 2nd ed, 2 vol. New York: Springer; 2005. p. 556-80. 
14. Abbott SL, Cheung WKW, Janda M. The genus Aeromonas: biochemical characteristics, atypical reactions, and phenotypic identification schemes. J Clin Microbiol. 2003;41:2348-57.

15. Bauer AW, Kirby WM, Sherris JC, Turck M. Antibiotic susceptibility testing by a standardized single disk method. Am J Clin Pathol. 1966;45:493-6.

16. CLSI. Methods for antimicrobial dilution and disk susceptibility testing of infrequently isolated or fastidious bacteria. 3rd ed. CSLI guideline M45. Wayne: Clinical and Laboratory Standards Institute; 2015.

17. Smith $P$. The performance of antimicrobial susceptibility testing programmes relevant to aquaculture and aquaculture products. FAO Fisheries and Aquaculture Circular No. 1191. Rome: FAO; 2019. p. 14-15

18. Smith P, Finneganb W, Ngoc T, Kronvalld G. Influence of incubation temperature and time on the precision of MIC and disc diffusion antimicrobial susceptibility test data. Aquaculture. 2018;490:19-24.

19. CLSI-EUCAST Polymyxin Breakpoints Working Group. 2016. Recommendations for MIC determination of colistin (polymyxin E) as recommended by the joint CLSI-EUCAST Polymyxin Breakpoints Working Group. https ://www.eucast.org/fileadmin/src/media/PDFs/EUCAST_files/Gener al_documents/Recommendations_for_MIC_determination_of_colis tin March 2016.pdf Accessed Dec 202019.

20. CLSI. Performance standards for antimicrobial susceptibility testing, 26th ed. CLSI Supplement M100S. Wayne: Clinical and Laboratory Standards Institute; 2016.

21. Magiorakos A, Srinivasan A, Carey RB, Carmeli Y, Falagas ME, Giske CG, et al. Multidrug-resistant, extensively drug-resistant and pandrugresistant bacteria an international expert proposal for interim standard definitions for acquired resistance. Clin Microbiol Infect. 2012;18:268-81.

22. R Core Team, R Foundation for Statistical Computing. R: A language and environment for statistical computing. https://www.R-project.org/ Accessed May 202019.

23. Rossolini GM, Walsh T, Amicosante G. The Aeromonas metallo- $\beta$ lactamases: genetics, enzymology, and contribution to drug resistance. Microb Drug Resist. 1996;2:245-52.
24. Fosse T, Giraud-Morin C, Madinier I. Phenotypes of beta-lactam resistance in the genus Aeromonas. Pathol Biol. 2003;51:290-6.

25. Moura A, Henriques I, Ribeiro R, Correia A. Prevalence and characterization of integrons from bacteria isolated from a slaughterhouse wastewater treatment plant. J Antimicrob Chemother. 2007;60:1243-50.

26. Berglund B. Environmental dissemination of antibiotic resistance genes and correlation to anthropogenic contamination with antibiotics. Infect Ecol Epidemiol. 2015;5:28564.

27. Cantas L, Shah SQA, Cavaco LM, Manaia CM, Walsh F, Popowska M, et al. A brief multi-disciplinary review on antimicrobial resistance in medicine and its linkage to the global environmental microbiota. Front Microbiol. 2013;4:96.

28. Hatosy SM, Martiny AC. The ocean as a global reservoir of antibiotic resistance genes. Appl Environ Microbiol. 2015;81:7593-9.

29. Rhodes G, Huys G, Swings J, Mcgann P, Hiney M, Smith P, Pickup RW. Distribution of oxytetracycline resistance plasmids between aeromonads in hospital and aquaculture environments: implication of Tn1721 in dissemination of the tetracycline resistance determinant Tet A. Appl Environ Microbiol. 2000;66:3883-900.

30. World Health Organization. Critically important antimicrobials for human medicine: ranking of antimicrobial agents for risk management of antimicrobial resistance due to non-human use. 5th revision 2016. https ://apps.who.int/iris/bitstream/10665/255027/1/9789241512220-eng.pdf. Accessed May 292019.

31. Jones BL, Wilcox MH. Aeromonas infections and their treatment. J Antimicrob Chemother. 1995;35:453-61.

\section{Publisher's Note}

Springer Nature remains neutral with regard to jurisdictional claims in published maps and institutional affiliations.
Ready to submit your research? Choose BMC and benefit from:

- fast, convenient online submission

- thorough peer review by experienced researchers in your field

- rapid publication on acceptance

- support for research data, including large and complex data types

- gold Open Access which fosters wider collaboration and increased citations

- maximum visibility for your research: over $100 \mathrm{M}$ website views per year

At $\mathrm{BMC}$, research is always in progress.

Learn more biomedcentral.com/submissions 